
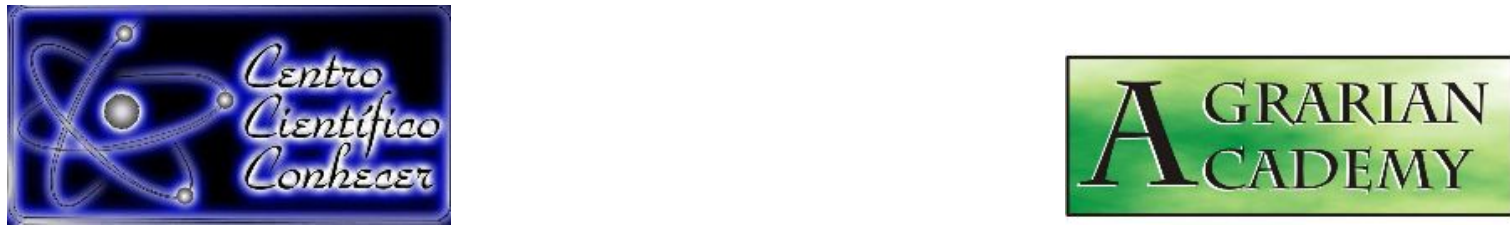

\title{
ANÁLISE ECONÔMICO-FINANCEIRA DA IMPLANTAÇÃO DO CULTIVO DE MILHO VERDE
}

Carolina Candida Rodrigues ${ }^{1}$, Francielle Wanderley Ribeiro ${ }^{1}$, Andrécia Cósmem da Silva², Matheus da Silva Araújo ${ }^{3}$

1 Discentes do Curso de Agronomia da Universidade Estadual de Goiás, Campus Ipameri, Ipameri, GO, Brasil. (carolagro28@gmail.com).

2 Professora Mestre da Universidade Estadual de Goiás, Campus Ipameri, Ipameri, GO, Brasil.

3 Doutorando em Solos e Nutrição de Plantas da Universidade de São Paulo, Campus ESALQ, Piracicaba, SP, Brasil.

Recebido em: 14/07/2018 - Aprovado em: 28/07/2018 - Publicado em: 31/07/2018 DOI: 10.18677/Agrarian_Academy_2018a3

O milho verde é uma olerícola que apresenta alto valor agregado, no entanto, é de suma importância o acompanhamento dos custos para implantação de um projeto, visto que a análise econômica possibilita ao produtor melhor verificação da rentabilidade do sistema adotado. Assim, o objetivo do estudo foi estimar os custos de produção e os indicadores de eficiência econômica da cultura do milho verde na região de Ipameri, Goiás. Foram analisados os fatores internos e externos da propriedade, possibilitando estipular o que, quanto, como e para quem produzir. Para análise econômica calculou-se o Custo Operacional Efetivo (COE) e Custo Operacional Total (COT), além disso, foram utilizados os seguintes indicadores econômicos: Valor Presente Líquido (VPL), Relação Benefício/Custo (RB/C) e PayBack Atualizado, para projeção em um período de cinco anos, com taxa de juros de $7 \%$ ao ano. Obteve-se um COE de $R \$ 4.025,14$. ha $^{-1}$ e COT de $R \$ 5.612,28$. ha $^{-1}$ para a implantação do projeto, com isso o VPL resultou um valor de $\mathrm{R} \$ 162.065,51$, enquanto o RB/C foi de 2,48 constatando o retorno de $R \$ 1,48$ a cada $R \$ 1,00$ investido e o Payback no $1^{\circ}$ ano. Quanto à análise de sensibilidade o projeto apresentou viabilidade econômica em todos os cenários estabelecidos. Portanto, conclui-se que o cultivo de milho verde demonstrou ser viável e de rápido retorno do capital investido, nas condições que foi realizado o estudo.

PALAVRAS-CHAVE: Custo de produção, indicadores econômicos, rentabilidade. 


\title{
ECONOMIC AND FINANCIAL ANALYSIS OF THE DEPLOYMENT OF THE CULTIVATION OF GREEN CORN
}

\begin{abstract}
The corn is a olerícola which features a high value aggregate, however, is of the utmost importance the follow-up costs for implementation of a project, because the economic analysis allows the producer better verification of the profitability of the system adopted. Thus, the aim of this study to examine the economic feasibility of growing corn on a property in the region of the Southeast. We analyzed the internal and external factors of property, making it possible to stipulate what, how much, how and for whom to produce. For economic analysis estimated the operating cost Effective (COE) and Total Operating Cost (TOC), also used the following economic indicators: net present value (NPV), benefit/cost (RB/C) and PayBack Updated, for projection over a period of 5 years, with interest rate of $7 \%$ per year. It was obtained a STRAIN of $R \$ 4.025,14$ ha $^{-1}$ and TOC of $R \$ 5.612,28$. ha $^{-1}$ for the implementation of the project, the VPL resulted a value of $R \$ 162.065,51$, while $R B / C$ was $R \$ 2,48$ noting the return of $R \$ 1,48$ every $R \$ 1,00$ invested and the Payback in the first year. As for the sensitivity analysis the project presented economic viability in all scenarios. Therefore, it is concluded that the cultivation of corn has been shown to be feasible and rapid return of invested capital, on the conditions that the study was conducted.
\end{abstract}

KEYWORDS: Cost of production, economic indicators, profitability.

\section{INTRODUÇÃO}

O milho (Zea mays L.) é uma planta originária da América Central, pertencente à família Graminae. Retratada como um dos cereais mais cultivados no mundo, principalmente por fazer parte da alimentação humana, animal e fornecer matéria-prima para a indústria (COUTO et al., 2017).

Em relação à produtividade do milho verde, a FIESP (2018) descreve que o Departamento de Agricultura dos Estados Unidos - USDA prevê no levantamento da safra mundial de milho 2018/19 uma produção 3,9\% menor nos EUA, devido a expectativa de menor produtividade e área plantada. A China como segundo maior produtor mundial deve ser recorde, com produção estimada de 225,0 milhões de toneladas, e para o Brasil, terceiro produtor mundial, projetou-se um aumento de $10,3 \%$ sobre o volume colhido na safra $17 / 18$, conforme a estimativa de área plantada e produtividade.

Tratando-se do milho verde, este é classificado como uma olerícola por apresentar alto valor agregado, cultivo intensivo e ser destinado majoritariamente ao consumo humano. Em consequência, refere-se à milho verde aquele que for colhido e consumido antes da total conversão do açúcar em amido, ou seja, quando os grãos ainda estiverem macios (LUZ et al., 2014).

No milho verde, a parte consumida diretamente e utilizada na elaboração de pratos tradicionais no Brasil é o grão, sendo comercializado basicamente na forma de espiga, enlatados e subprodutos, tais como, curau, suco e pamonha. Com isso, um dos atributos considerado pelo consumidor na comercialização do milho é o tamanho das espigas, sendo importante a escolha de cultivares destinada à produção de milho verde (SILVA et al., 2015).

Além de estar atento às questões técnicas para uma boa produção é essencial conhecer e dominar a parte financeira de um empreendimento, pensando nisso Silva et al., (2014) ressaltam que para que o produtor atenda a demanda e às 
necessidades do mercado consumidor, é fundamental que obtenham produtividades elevadas, sustentáveis e minimize os custos de produção.

O conhecimento dos custos de produção em uma propriedade rural possibilita verificar a rentabilidade, a lucratividade e a eficiência do sistema de produção adotado pelo produtor rural (RICHETTI, 2016). A aplicação de determinada tecnologia implica, diretamente, nos custos de produção e determina a produtividade da lavoura. Dessa forma, é de suma importância o acompanhamento dos custos que engloba o sistema de produção, pois, durante levantamento das despesas, é possível determinar tanto elementos responsáveis pelo bom desempenho da lavoura, como possíveis pontos de estrangulamentos do empreendimento agrícola (VASCONCELOS et al., 2002).

No entanto, como os estudos econômicos relacionados à cultura do milho verde ainda estão em processo de aperfeiçoamento, faz-se necessário o conhecimento dos custos e receitas para os produtores determinarem a viabilidade de suas atividades. Visto tal necessidade o estudo teve como objetivo estimar os custos de produção e os indicadores de eficiência econômica da cultura do milho verde na região de Ipameri, Goiás.

\section{MATERIAL E MÉTODOS}

A análise econômica foi desenvolvida em uma área experimental da Universidade Estadual de Goiás, Campus Ipameri, cujas coordenadas geográficas

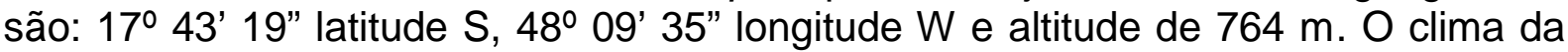
região segundo a classificação de Köppen é o clima tropical (AW), com estações bem definidas, frio e seco no inverno e quente e úmido no verão, expressando temperatura média de $20^{\circ} \mathrm{C}$ (ALVARES et al., 2013) e o solo da área foi classificado como Latossolo Vermelho-Amarelo Distrófico, conforme os parâmetros do Sistema Brasileiro de Classificação de Solos (EMBRAPA, 2013). Analisou-se a situação econômica da propriedade para observar os fatores internos, externos e com isso possibilitar a verificação da infraestrutura disponível, o quadro de funcionários e localização do empreendimento. Diante da realidade do mercado regional, averiguou-se a oferta e a demanda para o cultivo de milho verde, assim como os custos com insumos e mão de obra para implantação da cultura.

Considerou-se a estimativa do custo de milho verde em uma área de seis hectares no decorrer dos meses de agosto de 2017 a maio de 2018, com o intuito de realizar o levantamento do capital a ser investido determinou-se a correção do solo, que abrange calagem e gessagem, incluindo as despesas de frete, análise de solo e distribuição dos insumos. Além destes, houve o preparo do solo no qual realizou-se o processo de gradagem aradora e niveladora.

Perante o cenário estabelecido, a profundidade de plantio designada foi de três $\mathrm{cm}$, utilizando sementes do híbrido AG 1051, em espaçamento de $70 \mathrm{~cm}$ entre linhas, perfazendo uma densidade de 55.000 plantas.ha $^{-1}$ (ALVAREZ et al., 2006), no entanto, considerou-se que apenas $75 \%$ destas produzirão espigas de qualidade comercial, portanto a produtividade estipulada foi de 41.250 espigas.ha $^{-1}$. Na adubação de base estimou-se uma aplicação de $400 \mathrm{~kg} \mathrm{ha}^{-1}$ do formulado de NPK 04-30-16 e em cobertura $250 \mathrm{~kg} \cdot \mathrm{ha}^{-1}$ de ureia.

$\mathrm{Na}$ realização dos tratos culturais foram considerados: dessecação, tratamento de sementes, aplicação de defensivos e mão de obra essencial para a efetuação das atividades. A condução da cultura desenvolveu-se em sistema de sequeiro em decorrência da indisponibilidade hídrica suficiente para irrigação da 
área. Vale ressaltar que os maquinários para realização das atividades foram da Universidade, apenas a colheita foi terceirizada, visto que a propriedade analisada não possui tal máquina.

Levando em consideração as comercializações efetuadas no município de Ipameri-GO e região, adotou-se um valor de $R \$ 0,30$ a espiga, obtendo produtividade de 41.250 espigas. ha ${ }^{-1}$ conforme o manejo proposto e de acordo com a exigência do consumidor quanto ao padrão de espigas comerciais. Tais preços aplicados no estudo econômico foram apurados em empresas na região de análise, representando a verdadeira potencialidade da cultura considerada. Os coeficientes técnicos e o levantamento de dados primários foram obtidos por meio da aplicação de entrevistas junto a produtores que possuem conhecimento prático na área e por pesquisadores que atuam em estudos com a cultura analisada.

Deste modo, iniciou-se os cálculos para análise econômica a partir do fluxo de caixa, que conforme Erbano et al. (2014) pode ser determinado como um controle de entrada e saída do capital e assim permitir analisar o que será gerado financeiramente e como será aplicado em um determinado período de tempo. Para o levantamento do custo de produção foi utilizada a estrutura baseada na proposta por Matsunaga et al. (1976) do sistema de Custo Operacional Total (COT), e utilizada pelo Instituto de Economia Agrícola (IEA).

O Custo Operacional Efetivo (COE) constitui-se das despesas com insumos e serviços, investidos pelo agricultor por hectare para produzir determinada quantidade de produto. Enquanto o Custo Operacional Total (COT) trata-se do somatório do COE e das demais despesas do projeto que estão inclusos Funrural, percentagem de despesas não inclusas, percentagem com assistência técnica e oportunidade de terra, representando o custo total com a implantação do projeto (RAMBO et al. 2015). Além da análise econômica efetuada por meio dos custos operacionais foram estimados os indicadores econômicos:

Valor Presente Líquido (VPL) calculado pela Equação 1 constitui-se em calcular os valores correspondentes a todas as entradas e saídas de caixa, sendo a somatória de todos os capitais oriundos das receitas produzidas, subtraídas da soma das despesas ao longo da permanência do empreendimento e atualizados a partir da taxa de desconto do capital (LUCENA et al., 2016). Portanto, quando o VPL for maior que zero o projeto será viável, quando o valor for igual a zero não haverá lucro e quando o resultado for menor que zero, o projeto será inviável economicamente. Assim:

$$
V P L=\sum_{\mathrm{i}=0}^{\mathrm{n}} \frac{F C_{t}}{(1+i)^{t}}
$$

onde:

$\mathrm{VPL}=$ valor presente líquido;

$\Sigma=$ somatório;

$\mathrm{n}$ = número de fluxos de caixa;

$(\mathrm{fcx}) \mathrm{j}=$ fluxo de caixa do período $\mathrm{j}$;

$\mathrm{j}=$ período $(0,1,2, \ldots, \mathrm{n})$;

$\mathrm{i}$ = taxa de juros ou de desconto por período;

Relação Benefício/Custo (B/C) definida pela Equação 2 que consiste no retorno financeiro a partir da associação entre o valor presente de todos os componentes de custos de implantação e de despesas de operação, e as receitas AGRARIAN ACADEMY, Centro Científico Conhecer - Goiânia, v.5, n.9; p. 22 2018 
ou benefícios produzidos pelo projeto, sendo viável quando apresentar relação $B / C$ maior que 1 (ARAÚJO et al., 2015). Assim temos:

$$
\text { Relação } B / C=\frac{\sum_{j=0}^{n} R_{j} /(1+i)^{j}}{\sum_{j=0}^{n} C_{j} /(1+i)^{i}}
$$

onde:

$\mathrm{Rj}=$ receitas adquiridas no ano $\mathrm{j}$

I = taxa de desconto

$\mathrm{Cj}=$ custo adquiridos no ano $\mathrm{j}$

$\mathrm{n}=$ vida útil do projeto

Payback atualizado calculado pela Equação 3, no qual se determina o número de período necessário para repor o capital investido. Portanto é estabelecido como o produto do número de anos do projeto e a razão do valor presente dos lucros e valor presente dos investimentos (VERGARA et al., 2017). Dessa forma:

$$
\text { Payback atualizado }=\frac{\text { PVL (Investimentos) }}{\text { PVL (Lucros) }} \times 12 \text { meses }
$$

Realizou-se também a análise de sensibilidade, com o intuito de desenvolver possíveis projeções a partir de cenários que expressem a real situação ao produtor e assim verificar os possíveis riscos do projeto (VIRGENS et al., 2015). Para o qual, foram utilizados os seguintes indicadores econômicos: VPL, B/C e Payback. A análise foi disposta em quatro cenários, sendo eles:

Cenário I - Cenário real com produtividade de 225.000 espigas comercializadas a $\mathrm{R} \$ 0,30$ a unidade, com custo de produção de $\mathrm{R} \$ 34.725,96$.

Cenário II - Queda de 10\% na produtividade resultando 202.500 espigas comercializadas a $R \$ 0,30$ a unidade, com custo de produção de $R \$ 34.725,96$.

Cenário III - Produtividade de 225.000 espigas comercializadas a $\mathrm{R} \$ 0,30$ a unidade, com aumento de $10 \%$ nos custos de produção perfazendo um valor de $\mathrm{R} \$ 38.198,56$. Cenário IV - Queda de 10\% na produtividade totalizando 202.500 espigas comercializadas a $\mathrm{R} \$ 0,30$ a unidade, com acréscimo de $10 \%$ nos custos de produção atingindo um valor de $\mathrm{R} \$ 38.198,56$.

O projeto foi dimensionado para um período de cinco anos utilizando uma taxa de desconto de 7\% ao ano para o cálculo dos indicadores (BNDES, 2017), para a tabulação e análise dos dados foram utilizadas planilhas eletrônicas do programa Microsoft Excel ®.

\section{RESULTADOS E DISCUSSÃO}

Observa-se a planilha de estimativa de Custo Operacional Total (COT) para implantação de milho verde que durante o estudo um investimento de $\mathrm{R} \$ 33.673,68$ para a área total de 6 ha $^{-1}$ (Tabela 1), composto pelo Custo Operacional Efetivo (COE), Funrural, Despesas não inclusas que foi calculada para atender as eventuais despesas do projeto e Oportunidade de terra. 
TABELA 1 - Estimativa de Custo Operacional Total (COT) para implantação de milho verde na região sudeste de Goiás.

\begin{tabular}{|c|c|c|}
\hline Componente do custo & Valor.ha $^{-1}(\mathrm{R} \$)$ & Valor total.6 $\mathrm{ha}^{-1}(\mathrm{R} \$)$ \\
\hline A - Correção do solo & $\mathrm{R} \$ 895,00$ & $R \$ 5.370,00$ \\
\hline B - Preparo do solo & $R \$ 550,00$ & $R \$ 3.300,00$ \\
\hline C - Dessecação & $\mathrm{R} \$ 55,15$ & $\mathrm{R} \$ 330,90$ \\
\hline D - Plantio & $\mathrm{R} \$ 986,50$ & $R \$ 5.919,00$ \\
\hline E - Controle de pragas e doenças & $R \$ 278,49$ & $\mathrm{R} \$ 1.670,94$ \\
\hline F - Adubação de cobertura & $\mathrm{R} \$ 460,00$ & $\mathrm{R} \$ 2.760,00$ \\
\hline G - Colheita & $\mathrm{R} \$ 800,00$ & $R \$ 4.800,00$ \\
\hline $\begin{array}{l}\text { Custo Operacional Efetivo (COE) } \\
A+B+C+D+E+F+G\end{array}$ & $\mathrm{R} \$ 4.025,14$ & $\mathrm{R} \$ 24.150,84$ \\
\hline $\mathrm{H}$ - Funrural $^{1}$ & $\mathrm{R} \$ 284,63$ & $\mathrm{R} \$ 1.707,78$ \\
\hline | - Despesas não inclusas ${ }^{2}$ & $\mathrm{R} \$ 402,51$ & $\mathrm{R} \$ 2.415,06$ \\
\hline $\mathrm{J}$-Oportunidade de terra & $\mathrm{R} \$ 900,00$ & $R \$ 5.400,00$ \\
\hline $\begin{array}{l}\text { Custo Operacional Total (COT) } \\
\mathrm{COE}+\mathrm{H}+\mathrm{I}+\mathrm{J}\end{array}$ & $R \$ 5.612,28$ & $\mathrm{R} \$ 33.673,68$ \\
\hline \multicolumn{3}{|c|}{$\begin{array}{l}\text { Notas: } \\
1 \text { Refere-se a } 2,3 \% \text { (Funrural } 2017) \text { sobre a receita líquida. } \\
2 \text { Refere-se a } 10 \% \text { sobre o COE. } \\
{ }^{3} \text { Conforme valor praticado na região. } \\
\quad \text { Conforme a Figura } 1 \text { pode-se observar que a despesa com a condução do } \\
\text { plantio representou } 17,58 \% \text { do COT da atividade, sendo a mais onerosa de todo o } \\
\text { estudo, devido ao custo com adubação que é responsável por } 9,55 \% \text {, seguido do } \\
\text { custo com oportunidade de terra }(16,04 \%) \text {, o qual expressa um dos percentuais que } \\
\text { constituem as reservas obrigatórias para a efetivação do empreendimento, } \\
\text { posteriormente, correção do solo }(15,95 \%) \text { e colheita }(14,25 \%) \text {. }\end{array}$} \\
\hline
\end{tabular}

\section{Participação dos custos (\%)}

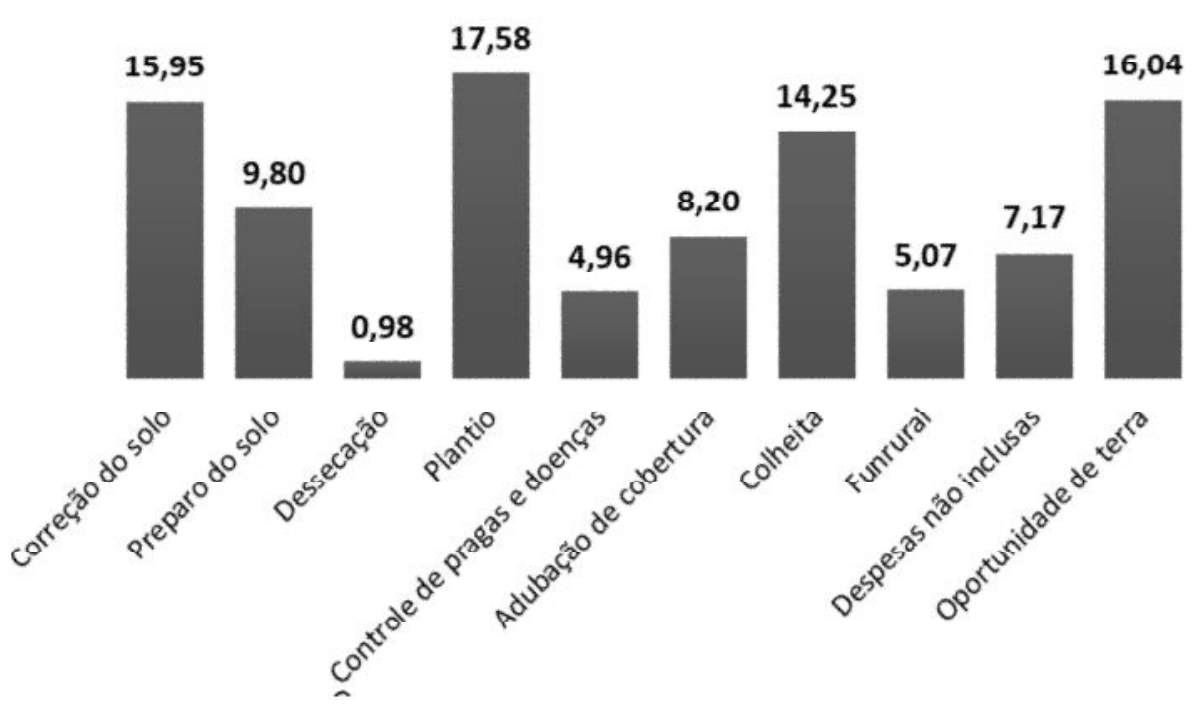

FIGURA 1- Distribuição da participação dos custos para implantação do milho verde em 1 hectare no estado de Goiás, 2018. 
Ao analisar o projeto é possível mensurar a receita bruta, esta é definida diretamente pelos fatores de produtividade e preços de comercialização, possibilitando assim averiguar a rentabilidade do mesmo. Na Tabela 2 estão dispostos os custos e as receitas referentes a 1 ha e 6 ha.

TABELA 2: Indicadores de eficiência econômica da produção de milho verde na região sudeste de Goiás.

\begin{tabular}{ccc}
\hline Descrição & Resultados (1 ha) & Resultados (6 ha) \\
\hline Produtividade média & 41.250 und. & 247.500 und. \\
Preço de comercialização & $\mathrm{R} \$ 0,30$ & $\mathrm{R} \$ 0,30$ \\
Receita Bruta & $\mathrm{R} \$ 12.375,00$ & $\mathrm{R} \$ 74.250,00$ \\
Custo Operacional Total (COT) & $\mathrm{R} \$ 5.612,28$ & $\mathrm{R} \$ 33.673,68$ \\
Receita Líquida & $\mathrm{R} \$ 6.762,72$ & $\mathrm{R} \$ 40.576,32$ \\
\hline
\end{tabular}

Em estudo realizado por Santos et al. (2009) com o híbrido XB 7012 o COT foi de $R \$ 1.534,76$. ha $^{-1}$ e a receita bruta de $R \$ 7.320,00$. ha $^{-1}$, tais valores foram inferiores aos obtidos no presente estudo, visto que houve um aumento no preço dos insumos e serviços na área agrícola, refletindo assim no COT da cultura, além disso é importante ressaltar que essa diferença resulta das diversas formas de condução da cultura, sendo que a área de estudo foi na região de Andradina/SP. Ademais, pode-se evidenciar que o valor de comercialização efetuado por Santos et al. (2009) foi de $R \$ 0,24$ por espiga, sendo inferior ao preço atual de $R \$ 0,30$, influenciando diretamente na receita bruta, bem como a população de 40.000 plantas.ha ${ }^{-1}$ sendo inferior à 55.000 plantas.ha $^{-1}$ do estudo, reduzindo assim a quantidade de espigas comercializáveis que segundo os autores foi de 30.250 espigas. ha ${ }^{-1}$.

Perante análise desenvolvida por Zárate et al. (2009) para produção de milho verde, foi possível constatar a receita líquida obtida no valor de $\mathrm{R} \$ 2.684,10$.ha $^{-1}$ sendo inferior ao valor de $\mathrm{R} \$ 6.762,72$ ha $^{-1}$ detectado no presente estudo. Entre os motivos da diferença apresentada importa explicitar o preço de comercialização estimada por Zárate et al. (2009), que foi de $\mathrm{R} \$ 0,10$ a espiga, consideravelmente inferior ao utilizado no presente trabalho, de $\mathrm{R} \$ 0,30$ a espiga, além disso o custo total de produção foi de $\mathrm{R} \$ 1.315,90 . \mathrm{ha}^{-1}$, menor que a deste estudo devido ao diferente manejo aplicado, como a ausência de adubação de cobertura e aplicação de fitossanitários químicos, sendo utilizado inseticida alternativo composto por alho. A produção de espigas comerciais foi de 40.000 espigas.ha $^{-1}$, sendo 1.250 espigas.ha ${ }^{-1}$ a menos que o atual estudo. Assim refletindo de forma significativa na receita líquida, tal divergência pode ser esclarecida visto que a cotação para comercialização do produto se fez em regiões distintas.

Para viabilidade econômica do milho verde é possível observar na Tabela 3 que analisando os custos e receitas da projeção de cinco anos verifica-se que a atividade demonstra lucratividade significativa, dado que o VPL é de $R \$ 162.065,51$, para 6 hectares.

TABELA 3: Indicadores econômicos atualizados à taxa de juros de $7 \%$ a.a. para a avaliação para o cultivo de milho verde em 6 hectares. Indicadores

\begin{tabular}{cc}
\multicolumn{3}{c}{ Indicadores } \\
\hline $\mathrm{VPL}$ & $\mathrm{R} \$ 162.065,51$ \\
$\mathrm{~B} / \mathrm{C}$ & 2,48 \\
Payback & $1^{\circ}$ ano \\
\hline AGRARIAN ACADEMY, Centro Científico Conhecer - Goiânia, v.5, n.9; & p. $25 \quad 2018$
\end{tabular}


Nota-se que o indicador econômico relação benefício/custo (B/C) apresentou valor de 2,48, constatando que a cada $R \$ 1,00$ investido no empreendimento haverá um retorno líquido de $R \$ 1,48$, atestando a viabilidade da atividade. Quando Aguiar et al. (2008) desenvolveram um estudo testando diferentes doses de nitrogênio/ureia em cobertura na cultura do milho, as doses que se aproximaram à utilizada no presente estudo foram, $180 \mathrm{~kg} \cdot \mathrm{ha}^{-1}$ e $360 \mathrm{~kg} \cdot \mathrm{ha}^{-1}$ de ureia, que obtiveram respectivamente, relação $B / C$ de 1,15 e 1,37 , sendo menores que a relação $B / C$ de 2,48 do estudo em questão. Tal valor foi inferior devido a forma de comercialização, onde vendeu-se a $R \$ 0,25$ o quilo do milho em grão sendo necessário maior quantidade de espigas para atingir um quilo, assim obtendo uma lucratividade muito baixa em relação à venda de cada espiga a $R \$ 0,30$. Além disso, as práticas de manejo desenvolvidas pelos autores foram reduzidas quando comparadas ao presente estudo, visto que não houve custos com correção do solo (calagem) e fitossanitários para controles de pragas e doenças.

A análise de sensibilidade visa certificar a estabilidade das atividades desenvolvidas no empreendimento, com esse intuito a mesma foi realizada a partir das variáveis que mais impactam nos resultados, sendo estas, custo e produção (Tabela 4).

TABELA 4: Análise de sensibilidade para o cultivo de milho verde em 6 hectares na região sudeste de Goiás, utilizando os indicadores econômicos B/C, VPL e Payback.

\begin{tabular}{cccc}
\hline \multicolumn{3}{c}{ Análise de Sensibilidade } \\
\hline Cenários & $\mathrm{B} / \mathrm{C}$ & $\mathrm{VPL}$ & Payback \\
\hline I & 2,48 & $\mathrm{R} \$ 162.065,51$ & 10 ano \\
II & 1,95 & $\mathrm{R} \$ 131.555,63$ & 10 ano \\
III & 1,92 & $\mathrm{R} \$ 144.861,33$ & 10 ano \\
IV & 1,70 & $\mathrm{R} \$ 114.351,34$ & 10 ano
\end{tabular}

Legenda: Cenário I: Cenário real; Cenário II: Redução de 10\% na produtividade; Cenário III: Aumento de $10 \%$ nos custos; Cenário IV: Redução de $10 \%$ na produtividade e aumento de $10 \%$ nos custos.

Em conformidade com os resultados obtidos na tabela anterior, pode-se constatar que nos cenários obteve viabilidade econômica para implantação da cultura, assegurando ao produtor que mesmo no cenário pessimista, no qual ocorre queda na produção e aumento nos custos haverá retorno financeiro do investimento. Portanto, a realização desta análise possibilita com que o empreendedor obtenha uma margem de segurança para a implantação do projeto.

Vale explicitar que análises econômicas auxiliam na tomada de decisão ao implantar um projeto, dado que permite melhor reconhecimento de todas as etapas produtivas, custos e lucratividades do empreendimento. Sendo importante para investir em uma atividade lucrativa e que dê estabilidade ao investidor.

Tendo como base os indicadores econômicos analisados, todos demonstraram viabilidade econômica, sendo o B/C de 2,48, VPL de $R \$ 162.065,51$ e Payback no $1^{\circ}$ ano, evidenciando assim os aspectos positivos para implantação de milho verde na região de estudo. Sendo válido ressaltar que o projeto apresenta suas especificidades, podendo variar os resultados conforme o manejo da cultura e a região de implantação. 


\section{CONCLUSÕES}

O cultivo de milho verde mostrou-se economicamente viável nas condições em que se realizou o estudo, pois os indicadores de rentabilidade econômica foram positivos, retratando que essa atividade é de rápido retorno do investimento, apresentando boa potencialidade de geração de renda.

\section{REFERÊNCIAS}

AGUIAR, R. A.; SILVEIRA, P. M.; MOREIRA, J. A. A.; WANDER, A. E. Análise econômica de diferentes práticas culturais na cultura do milho (Zea mays L.). Pesquisa Agropecuária Tropical, v. 38, n. 4, p. 241-248, 2008. Disponível em: <http://www.redalyc.org/pdf/2530/253020303003.pdf>. doi: 10.1127/09412948/2013/0507. Acesso em: 20 mar. 2018.

ALVARES, C. A.; STAPE, J. L.; SENTELHAS, P. C.; GONÇALVES, J. L. M.; SPAROVEK, G. Köppen's climate classification map for Brazil. Meteorologische Zeitschrift, v. 22, n. 6, p. 711-728, 2013. Disponível em: <https://doi.org/10.1127/0941-2948/2013/0507>. doi: 10.1127/0941-2948/2013/0507. Acesso em: 10 mar. 2018.

ALVAREZ, C. G. D.; PINHO, R. G. V.; BORGES, I. D.; Avaliação de características agronômicas e de produção de forragem e grãos de milho em diferentes densidades de semeadura e espaçamentos entre linhas. Ciência e Agrotecnologia, v. 30, n.3, p. 402-408, maio/jun, 2006. Disponível em: <http://www.scielo.br/pdf/cagro/v30n3/v30n3a03>. Acesso em: 15 mar. 2018.

ARAÚJO, E. F.; AGUIAR, A. S.; BARBOSA, M. V. R.; BRITO, W. C.; CORDEIRO, S. A. Rentabilidade de plantios de acácia-australiana e de sistema de integração lavoura-pecuária-floresta no sudoeste do Piauí. Nativa, Sinop-MT, v. 03, n. 04, p. 268-275, 2015.2 Disponível em: <https://www.researchgate.net/publication/287643526>. doi: 10.14583/23187670.v03n04a08. Acesso em: 19 mai. 2018.

BNDES - Banco Nacional de Desenvolvimento Econômico e Social. Brasília: BNDES. Taxa de juros de longo prazo. Disponível em: https://www.bndes.gov.br/wps/portal/site/home/financiamento/guia/custosfinanceiros/taxa-juros-longo-prazo-tjlp. Acesso em: 20 set. 2017.

COUTO, C. A.; SILVA, É. M.; SILVA, A. G.; OLIVEIRA, M. T. P.; VASCONCELOS, J. C.; SILVA, A. R.; SOBREIRA, E. A.; MOURA, J. B. Desempenho de Cultivares de Milho Destinados para Produção de Milho Verde e Silagem. Journal of Social, Technological and Environmental Science, v. 6, n.1, p. 232-251, 2017. Disponível em: <http://periodicos.unievangelica.edu.br/index.php/fronteiras/article/view/1323>. doi: https://doi.org/10.21664/2238-8869.2017v6i1.p232-251. Acesso em: 20 abr. 2018.

EMBRAPA. Sistema brasileiro de classificação de solos. 3 ed. Brasília: Embrapa Solos, 2013. 201p. 
ERBANO, B. L; THEISEN, D. G.; VEBER, E. E.; SOUZA, M. E. S.; SOUZA, A.; APEL, R. Fluxo de caixa. Maiêutica - Estudos Contemporâneos em gestão organizacional. V. $1, \mathrm{n}^{\circ}$ 1, p. 131-134. 2014. Disponível em: < https://publicacao.uniasselvi.com.br/index.php/GESTAO_EaD/article/view/1248/407> . Acesso em: 22 abr. 2018.

FIESP - Federação das Indústrias do Estado de São Paulo. Safra Mundial de Milho 2018/19. Disponível em: <http://www.fiesp.com.br/indices-pesquisas-epublicacoes/safra-mundial-de-milho-2/attachment/file-20180514143657boletimmilhomaio2018/>. Acesso em: 06 jun. 2018.

LUCENA, H. D.; PARAENSE, V. C.; MANCEBO, C. H. A. Viabilidade econômica de um sistema agroflorestal com cacau e essências florestais de alto valor comercial em Altamira-PA. Revista de Administração e Negócios da Amazônia, v.8, n.1, 2016. Disponível em: http://www.periodicos.unir.br/index.php/rara/article/view/1566/1524>. doi: 10.18361/2176-8366/rara.v8n1p73-84. Acesso em: 18 mai. 2018.

LUZ, J. M. Q.; CAMILO, J. S.; BARBIERI, V. H. B.; RANGEL, R. M.; OLIVEIRA, R. C. Produtividade de genótipos de milho doce e milho verde em função de intervalos de colheita. Horticultura Brasileira, v. 32, n. 2, p. 163-167, 2014. Disponível em: < http://editor.horticulturabrasileira.com.br/index.php/HB/article/view/49>.

Doi: https://doi.org/10.1590/hb.v32i2.49. Acesso em: 08 abr. 2018.

MATSUNAGA, M.; BEMELMANS, P. F.; TOLEDO, P. E. N.; DULLEY, R. D.; OKAWA, H.; PEDROSO, I. A. Metodologia de custos de produção utilizada pelo IEA. Agricultura em São Paulo, São Paulo-SP, v. 23, n. 1, p. 123139, 1976. Disponível em: < http://www.iea.sp.gov.br/out/verTexto.php?codTexto=11566>. Acesso em: 24 mar. 2018.

RAMBO, J. R.; TARSITANO, M. A. A.; KRAUSE, W.; LAFORGA, G.; SILVA, C.; Análise financeira e custo de produção de banana-maçã: um estudo de caso em Tangará da Serra, Estado do Mato Grosso. Informações econômicas, São Paulo, v.45, n.5, 2015. Disponível em: < http://www.iea.sp.gov.br/ftpiea/publicacoes/ie/2015/tec4-1015.pdf>. Acesso em: 24 mai. 2018.

RICHETTI, A. Viabilidade econômica da cultura da soja na safra 2016/2017, em Mato Grosso do Sul. Embrapa Agropecuária. 2016, 5p. (Comunicado técnico 211). Disponível em: https://ainfo.cnptia.embrapa.br/digital/bitstream/item/146045/1/COT2016211.pdf>. Acesso em: 28 nov. 2017.

SANTOS, N. C. B.; TARSITANO, M. A. A.; ARF, O.; MATEUS, G. P.; Análise econômica do consórcio de feijoeiro e milho-verde. Revista Brasileira de Milho e Sorgo, v.8, n.1, p.1-12, 2009. Disponível em: <http://rbms.cnpms.embrapa.br/index.php/ojs/article/view/266/pdf_169>. doi: http://dx.doi.org/10.18512/1980-6477/rbms.v8n1p1-12. Acesso em: 14 nov. 2017. 
SILVA, G. C.; SCHMITZ, R.; SILVA, L. C.; CARPANINI, G. G.; MAGALHÃES, R. C. Desempenho de cultivares para produção de milho verde na agricultura familiar do sul de Roraima. Revista Brasileira de Milho e Sorgo, v. 14, n. 2, p. 273-282, 2015. Disponível em:

http://rbms.cnpms.embrapa.br/index.php/ojs/article/view/562/pdf_425>. doi: http://dx.doi.org/10.18512/1980-6477/rbms.v14n2p273-282. Acesso em: 20 set. 2017.

SILVA, G. F.; OLIVEIRA, F. H. T.; PEREIRA, R. G.; DIÓGENES, T. B. A.; NOVO JÚNIOR, J.; SOUZA FILHO, A. L. Doses de nitrogênio e de fósforo recomendadas para produção econômica de milho verde em Mossoró-RN. Magistra, Cruz das Almas, v. 26, n. 4, 2014. Disponível em: < https://magistraonline.ufrb.edu.br/index.php/magistra/article/view/482/261>. Acesso em: 26 set. 2017.

VASCONCELOS, R. C.; PINHO, R. G. V.; REIS, R. P.; LOGATO, E. S. Estimativa dos custos de produção de milho na safra agrícola 1998/1999 no município de Lavras-MG. Ciências Agrotecnológicas, Lavras, v.26, n.2, p.283-291, 2002. Disponível em: http://www.editora.ufla.br/index.php/component/phocadownload/category/45-volume26-numero-2?download=786:vol26numero2>. Acesso em: 25 abr. 2018.

VERGARA, W. L. H.; OLIVEIRA, J. P. C.; BARBOSA, F. A.; YAMANARI, J. S. Análise de viabilidade econômico-financeira para aquisição de uma unidade de armazenagem de soja e milho. Revista Gepros, Ano 12, no 1, p. 41-61, 2017. Disponível em: < http://revista.feb.unesp.br/index.php/gepros/article/view/1598/755>. doi: 10.15675/gepros.v12i1.1598. Acesso em: 27 mai. 2018

VIRGENS, A. P.; FREITAS, L. C.; LUZ, D. S.; MOREIRA, A. C. D. Análise econômica e de sensibilidade em projetos de reflorestamentos no estado da Bahia. Enciclopédia Biosfera, Goiânia, v.11, n.21, p.120-127, 2015. Disponível em: < http://www.conhecer.org.br/enciclop/2015b/agrarias/analise $\% 20$ economica $\% 20 \mathrm{e} \% 20$ de\%20sensibilidade.pdf>. Acesso em: 22 mar. 2018.

ZÁRATE, N. A. H.; VIEIRA, M. C.; SOUSA, T. M.; RAMOS, D. D. Produção e renda líquida de milho verde em função da época de amontoa. Semina: Ciências Agrárias, Londrina, v.30, n. 1, p.95-100, 2009. Disponível em: < http://www.redalyc.org/html/4457/445744091011/>. Acesso em: 09 dez. 2017. 